Engineering and Computational Mechanics Volume 170 Issue EM3

Air-water interactions in urban drainage systems

Wright, Vasconcelos and Lewis
Proceedings of the Institution of Civil Engineers

Engineering and Computational Mechanics 170 September 2017 Issue EM3 Pages 91-106 http://dx.doi.org/10.1680/jencm.16.00024 Paper 1600024

Received 19/09/2016

Published online 24/08/2017

Keywords: hydraulics \& hydrodynamics/pipes \& pipelines/

sewers \& drains

\title{
Air-water interactions in urban drainage systems
}

\section{Steven J. Wright PhD}

Professor, Department of Civil and Environmental Engineering, University of Michigan, Ann Arbor, MI, USA (corresponding author: sjwright@umich.edu) (Orcid:0000-0002-5261-5299)

\section{Jose G. Vasconcelos PhD}

Associate Professor, Department of Civil Engineering, Auburn University, Auburn, AL, USA

\author{
James W. Lewis PhD \\ Research Hydraulic Engineer, US Army Corps of Engineers, Coastal and
} Hydraulics Laboratory, Vicksburg, MS, USA

Storm water and combined sewer systems are subject to rapid filling during intense rainfall events. These large-sized systems require a significant amount of air to be vented during filling. Several systems have experienced operational problems such as structural damages and geyser release through ventilation shafts. Observations from one storm water conveyance tunnel and laboratory experiments suggest that entrapment of large discrete volumes of air during rapid filling can explain geyser formation as well as large system pressures associated with the compression of trapped air. Only modest system pressures are required to produce geysers. Descriptions of several air-water interactions are presented to advance the hypotheses for the occurrence of the two detrimental phenomena. Requirements for numerical models to analyse rapidly filling conduits are discussed. A review of the existing modelling frameworks is presented. Some limitations to these models are discussed along with a discussion of possible model enhancements.

\section{Notation}

$c \quad$ celerity of elementary free surface flow disturbance

D conduit diameter

$D_{\mathrm{R}} \quad$ diameter of the vertical riser

$D_{\mathrm{T}} \quad$ diameter of the horizontal conduit (tunnel)

g acceleration due to gravity

$h \quad$ rise height of the sewer geyser

$T \quad$ top width of free surface flow cross-section

$t \quad$ cross-sectional area of pipe

$U \quad$ air intrusion velocity

$V \quad$ vertical velocity of discharging sewer geyser

$V_{\text {air }} \quad$ trapped air volume

$y \quad$ air thickness behind the horizontal intrusion

$Z_{\mathrm{m}} \quad$ maximum vertical rise of water above air intrusion

$Z_{\mathrm{s}} \quad$ air rise in vertical intrusion before it breaks through the interface

$\Delta P \quad$ pressure difference driving sewer geyser

$\rho_{\mathrm{m}} \quad$ mass density of air-water mixture

$\rho_{\mathrm{w}} \quad$ water density

\section{Introduction}

Combined sewer systems that collect both storm water and sanitary sewage are a relic of past practices as drainage projects were implemented in urban areas to replace open sewers. Although such practice is no longer allowed in most developed countries, there are still many urban areas with combined systems; an estimated 746 communities are serviced by combined systems in the USA alone (US EPA, 2015). A major issue related to combined sewer systems is that a significant rainfall will typically overwhelm the hydraulic capacity of a system, resulting in combined sewer overflows (CSOs) to surface water bodies to prevent basement flooding and other undesirable occurrences. Following passage of the US Clean Water Act in 1972 (US EPA, 1972), action was taken to modify combined sewer systems to reduce the frequency and volume of CSOs. The strategy that is typically implemented involves addition of deep storage to a combined sewer system such that the flow can be diverted to storage during intense rainfall events and then pumped back into the collection system once the rainfall run-off has subsided. These storage systems have been or are being implemented in many urban areas in response to regulatory requirements, with about 150 communities in the USA under a regulatory consent agreement to modify their collection systems along with other improvements to reduce the volume of overflows. Such projects are extremely expensive, costing multiple billions of dollars (US) in large urban areas. This constraint typically produces engineering compromises such that CSOs are not completely eliminated, but the system is sized to limit the number to a few per year.

The largest and earliest implemented tunnel storage system in the USA was for Chicago, Illinois, referred to as Tarp (tunnel and reservoir project) with more than $170 \mathrm{~km}$ of tunnels up to a maximum diameter of about $10 \mathrm{~m}$. This complex project was initiated in 1975 and is scheduled for completion in 2029 and will most likely involve construction costs on the order of US $\$ 10$ billion. The tunnel is normally empty and then fills 
rapidly during a major precipitation event. With the large storage capacity, a large air volume must be displaced by the filling process and the design provisions must be made to vent this air adequately during the essentially uncontrolled filling process. This issue was not adequately addressed in the design of Tarp and other early CSO storage systems, with the unexpected occurrence of air/water flows commonly referred to as geysers erupting explosively through access manholes and other vertical shafts. Awareness of geysers and other issues presumably related to air expulsion from rapidly filling tunnels has led to a heightened concern for identifying proper engineering approaches to eliminate potential problems. Early research work on the subject apparently failed to recognise the true nature of the problem, but more recent studies have begun to address the nature of air/water interactions in these tunnel systems. It is noted that the problem is not unique to combined sewer storage tunnels as storm water collection systems are also subject to rapid filling and may exhibit similar behaviour. Refilling of large-diameter water transmission pipelines following maintenance or repairs is a related topic that has been subject to similar considerations (e.g. Liou and Hunt, 1996), but is a more straightforward problem since the filling can be somewhat controlled. This manuscript provides a review of research performed primarily over the last 15 years to investigate the phenomenon of air/water interactions during rapid filling of large-diameter conduits to understand the relevant phenomena so that appropriate designs can be implemented. Both the problem of geyser formation and the occurrence of large system pressures due to compression of trapped air are considered. Those included are observations from laboratory investigations, a limited set of observations from full-scale systems and numerical methods suitable for purposes of predicting the flow behaviour in rapidly filling systems. Conclusions and recommendations for further study are presented at the end of the article.

\section{Background}

A CSO storage tunnel is typically constructed on the order of $30 \mathrm{~m}$ or more below grade to be located below all conventional drainage systems and other infrastructures. Often the tunnel has multiple branches with numerous dropshafts conveying inflows into the tunnel at or near the locations of previous overflow discharge points. The tunnel is typically laid on a small grade so that the pumping of water back into the conveyance system following the rainfall run-off event occurs at a downstream location where the water can drain by gravity. This low end of the system typically fills during the early stages of the run-off event with a filling front that propagates towards the upstream end of the tunnel. Figure 1 indicates an early version of a proposed storage tunnel for Washington, DC, USA, with several branching tunnels in order to intercept all existing overflows. This situation makes it difficult to discuss general system geometries, while the hydrologic complexity of major rainfall events also makes it difficult to define typical tunnel filling responses. Figure 1 depicts a simulation of the filling process during a major rainfall event at a time when

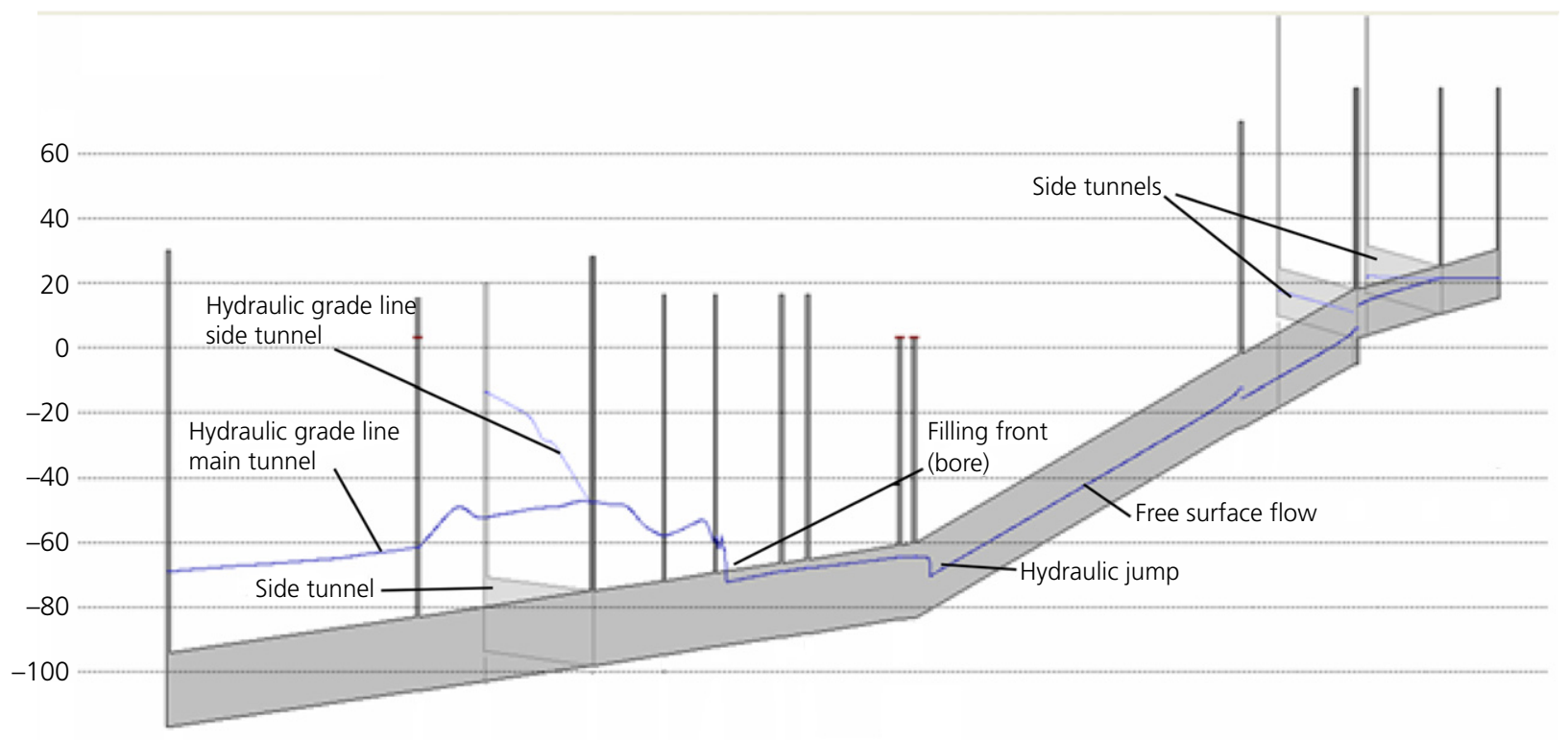

Figure 1. Profile view of the main branch of Washington, DC combined sewer storage tunnel with overflow and other access locations indicated as vertical risers and branch tunnel connections indicated 
the downstream end of the tunnel has become surcharged and the filling front is propagating towards the upstream end of the system (more details are presented in the paper by Lautenbach et al. (2008)). In this figure, there are three lateral tunnel segments that join the main tunnel and the hydraulic grade line is indicated in those as well. The flow is generally left to right although the filling front is propagating in the opposite direction. Note that a hydraulic jump is also indicated just upstream from the change in slope.

\subsection{Observed phenomena in rapidly filling urban drainage systems}

Several urban drainage systems have been reported to have experienced operational problems, often in the form of anecdotes that are not well documented. Generally, these fall into two categories.

- Elevated system pressures, resulting in manhole cover blow-offs or, in some cases, damage to the drainage system (Li and McCorquodale, 1999; Vasconcelos and Wright, 2007a; Zhou et al., 2002a). Typically, no measurements exist to document the magnitudes of the pressures that were experienced or their history from which a better understanding of the physical processes might be developed.

- A phenomenon that has been referred to as geysering after the superficial resemblance to steam geysers that are manifest as periodic eruptions of steam and water from underground formations. The term is not to indicate that steam is involved with geysers in urban drainage systems. Nielsen and Davis (2009) also report observations of geyser formation in a hydropower tunnel subject to rapid filling. In the early literature related to this topic, the term geyser is generally used in an ambiguous context. More recently, this writer and collaborators have been able to shed more light on the mechanisms for sewer geyser formation and these are discussed below. Images from video recordings of the observed geyser events are presented in Figure 2 - from Minneapolis, Minnesota, USA in Figure 2(a) and from Edmonton, Alberta, Canada in Figure 2(b).

Shortly after it became operational, the Chicago Tarp system experienced geysers during rainfall events at various locations in the system. The first comprehensive studies related to the geyser phenomenon were performed in response to these occurrences. Although conclusions from these studies are not exhaustive for reasons discussed below, the recommendations arising from these studies were to throttle gates regulating inflow into the tunnel system to reduce the water inertia in the filling tunnel as it becomes surcharged. The size and complexity of the system made it necessary to initiate the throttling process when the tunnel was just over half full. One

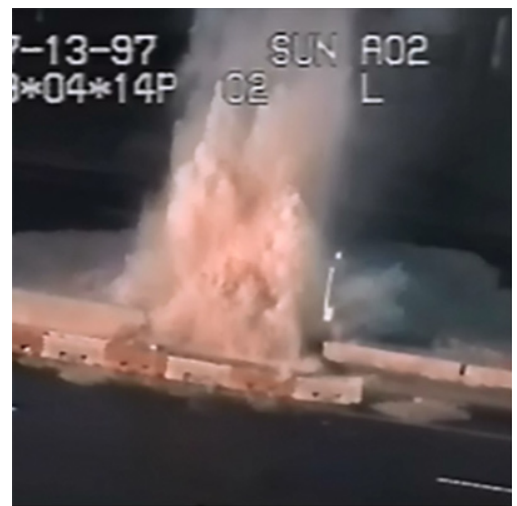

(a)

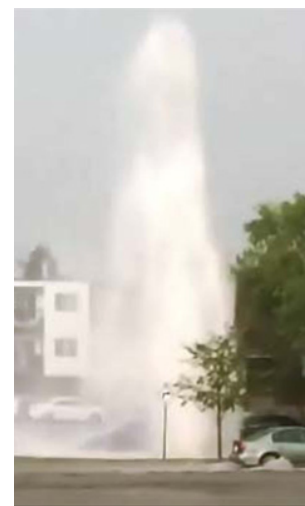

(b)
Figure 2. Images from videotapes of geysers in sewer systems in: (a) Minneapolis, Minnesota, USA and (b) Edmonton, Alberta, Canada

consequence of the throttling process is that reducing tunnel inflows increases the overflow to the environment and it is possible that run-off could be subsiding just as the throttling begins (resulting in unnecessary overflow). In addition, there have been events in recent years where a severe storm resulted in loss of electrical power to the gates and they could not be closed, resulting in geyser formation in the system. A better understanding of the physical processes during rapid filling could potentially lead to modifications to system design and/or operation that could mitigate geyser formation and other undesirable system performance.

\subsection{Tentative explanations for geyser formation}

Early attempts at modelling the presumed conditions that lead to geyser formation focused on inertial surge (e.g. Guo and Song, 1990). A typical example of inertial surge is the flow generated in penstocks in hydroelectric facilities following load rejection. If a drainage conduit is still filling in a free surface state, strong surges are not possible since the compressibility of the air above the filling flow provides for direct mitigation of strong inertial effects. Therefore, inertial surge is only possible once the filling conduit has transitioned to a surcharged state, in at least some portion of the conduit. It could be possible, for example, for a filling front of the sort depicted in Figure 1 (a bore or moving hydraulic jump that transitions to a surcharged state) to generate an inertial surge when it reaches a transition to a smaller upstream diameter such as at the right side of the figure. The filling front impinging on this location can create a reflection that propagates pressure fluctuations throughout the system and, in principle, could create sufficiently large system pressures to cause water to rise through vertical shafts and raise water above the top of the shaft, spilling out through a manhole. Guo (1989: p. 575) 
justifies considering inertial surge as the cause of geysers by the following '...if the water level rises above the ground surface, the geyser occurs. It has been ascertained that if the dropshaft is ventilated, as most are, the cover could not be blown off by air pressure alone. That is, most blow-offs are caused by the impact forces of the rising water. Therefore, it is sufficient to study the hydrodynamics alone'. There are reasons to doubt this as an explanation. Surge models generally fail to predict pressure rises large enough to eject water several tens of metres into the air as depicted in Figures 2(a) and 2(b). A close examination of the two figures suggests that the geyser is a mixture of air and water. Such a situation would not be readily tractable to analysis with an inertial surge model. It will be shown below that the only existing field evidence collected during an observed geyser event cannot support an inertial surge description of the event. Moreover, laboratory observations provide strong support for an air/water interaction.

One possible explanation is that the rapid filling process does not uniformly expel the air above the surface of the rising water in the conduit due to limited ventilation opportunities, the complex nature of the filling process with multiple inflows and the interaction with complex conduit geometries. As the filling process proceeds, large discrete pockets of air become trapped within an otherwise surcharged system and as these pockets migrate along the crown of the conduit due to imposed forces, their arrival at a vertical ventilation shaft or manhole will initiate geyser formation. This is not to imply that other mechanisms cannot be responsible for return of water to grade, but the spectacular eruptions such as in Figure 2 seem to require an air interaction as an explanation. Two explanations are likely as to why earlier studies did not focus on this mechanism: $(a)$ the problem of inertial surge is more familiar to civil engineers and was a simple explanation to offer; $(b)$ the equations describing inertial surge are more straightforward to formulate and solve, offering an appealing analysis approach. Only when observations of phenomena that are incompatible with inertial surge could not be ignored was the need for an alternative approach indicated.

\section{Observations of geysers}

\subsection{Field observation}

In the internet world, for example on YouTube, there are many video clips of sewer geysers, often with incorrect or partial information regarding their location and origin. There are several clips of the same manhole shown in Figure 2(a). Investigation has indicated that the video was acquired by the St. Anthony Falls Laboratory (University of Minnesota) as part of a study for the Minnesota Department of Transportation. The study was performed due to frequent formation of geysers at this location in a storm water tunnel and also included measurements of pressures and velocities within the tunnel. It was also possible to obtain general information on the geometric details of the system and ultimately a set of pressure and velocity data from an event that occurred on the morning of 11 July 2004. Two pressure transducers and a velocity probe were installed in the tunnel (Sigma velocity-area flow meter), with $5 \mathrm{~min}$ sample frequency. The pressure transducers were located 0.47 and $2.88 \mathrm{~m}$ above the tunnel invert. Velocities and pressures were recorded at 5 min intervals until the water level began to rise in the tunnel. Automatic controls on pressure sample frequency resulted in sample intervals of between 1 and $5 \mathrm{~s}$ depending on the water level. These results are reported in papers by Wright et al. (2011a, 2011b).

Nine independent geysers were observed in the video recording of the event on 11 July 2004; although there is some variability, each geyser lasted for about 10-25 s with about 75-90 s separating the onset of successive geysers. The velocity record indicates that the tunnel velocity was relatively constant at about $1 \mathrm{~m} / \mathrm{s}$ between about 5.30 and 8.50 a.m. with no indication of fluctuations that would suggest inertial oscillations in the conduit although the sample interval of $5 \mathrm{~min}$ makes definite conclusions impossible. The pressure records are even more revealing. The pressure history (lower pressure transducer) spanning the entire sequence of geysers is presented in Figure 3. The measured pressure head is increased by $0.47 \mathrm{~m}$ so that the pressure head is relative to the tunnel invert. Superimposed on the pressure trace are the timing of the visual observations of individual geysers and the elevation of the tunnel crown. The tunnel is indicated to exist in a surcharged state between $\sim 5.29$ and 5.46 a.m., spanning the duration of the geyser event $(\sim 5.35-5.44$ a.m.). There is no evidence of inertial oscillations in the pressure record. It should also be noted that the authors have obtained video recordings from several geysers in various systems; these recordings are generally only from the discharge from the vertical shaft. In most instances, individual geyser events tend to last at least $15 \mathrm{~s}$ and sometimes for the entire duration of the video which approaches $30 \mathrm{~s}$.

Figure 4 presents a portion of these data over about $5 \mathrm{~min}$ of the recording during the middle of the geyser event. In general, the pressure is seen to follow a gradual rise and fall associated with the rainfall run-off event as indicated in Figure 3. The onset of an individual geyser is followed by a pressure drop that lasts until about the end of the geyser event after which the pressure tends to recover to the overall gradual trend. Several observations can be made regarding the data presented in the figures. First, the pressure head relative to the tunnel invert never went above about $6 \mathrm{~m}$ during the entire event. Since the tunnel invert is $28.6 \mathrm{~m}$ below grade, the discussion by Guo (1989) would exclude the possibility of geysers as the hydraulic grade line never approaches the ground surface. This 


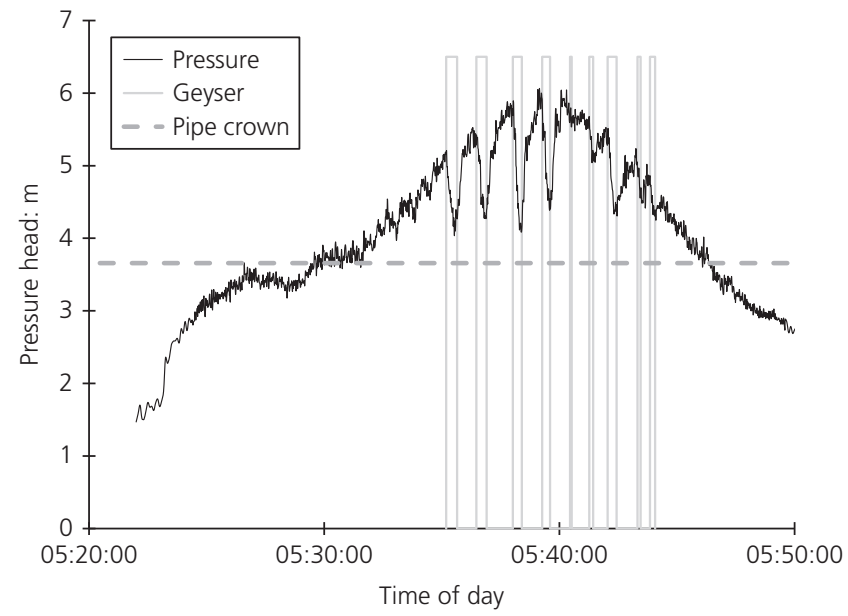

Figure 3. Pressure record scanning the entire geyser event of 11 July 2004 . Tunnel invert is $28.6 \mathrm{~m}$ below grade

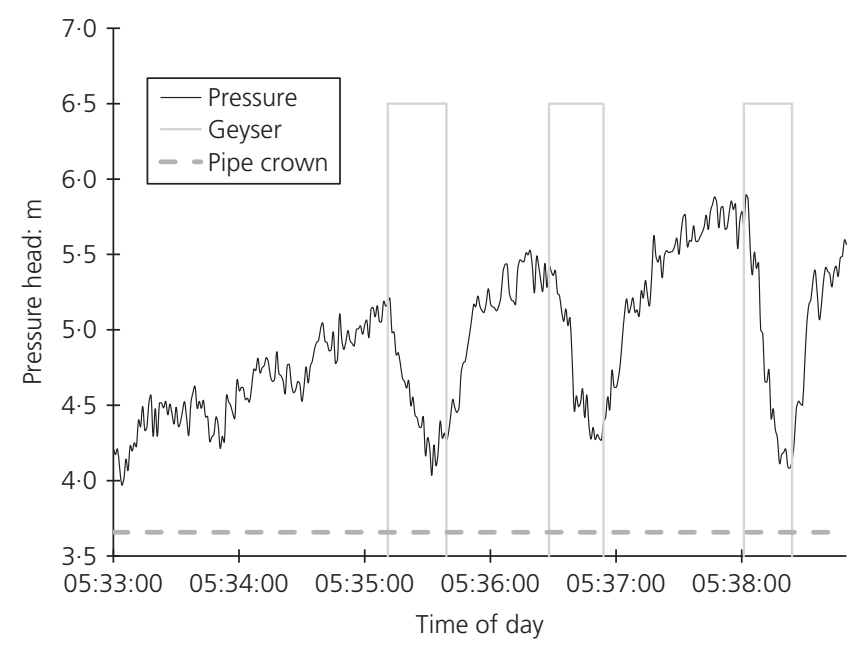

Figure 4. Pressure record of individual geyser events

clearly indicates that some other mechanism must be invoked to explain the observed geysers. This observation is also significant in that it illustrates that visually violent geyser events such as indicated in Figure 2 are not necessarily associated with extreme pressures.

Another observation is related to the estimated geyser discharge. It is estimated from the video recording that the geyser height is $\sim 20 \mathrm{~m}$ and the jet exit velocity can be estimated by the simple conversion of velocity to elevation head as $V^{2} /(2 \boldsymbol{g})=h$ with $h$ being the rise height of the water jet. Using $h=20 \mathrm{~m}$ would result in an exit velocity $V$ of $19 \cdot 8 \mathrm{~m} / \mathrm{s}$. With this jet exit velocity, an upward discharge of $93 \mathrm{~m}^{3} / \mathrm{s}$ through the manhole would be required if the geyser consisted of a single-phase water jet. This compares to a tunnel discharge of $<9 \mathrm{~m}^{3} / \mathrm{s}$ indicated by the measured tunnel velocities during the geyser events. This indicates that the jet seen in Figure 2(a) must contain only a small percentage of water by volume. This possibility allows for the development of the estimated large discharge velocity with relatively low tunnel pressures. Consider that a pressure difference can drive an air-water mixture according to the approximation $\Delta P \sim \rho_{\mathrm{m}} V^{2}$ with the air/water mixture at a density $\rho_{\mathrm{m}} \ll \rho_{\mathrm{w}}$ with $\rho_{\mathrm{w}}$ being the water density. Using this relation, a maximum observed pressure head (relative to the tunnel crown) from Figure 3 of about $2.5 \mathrm{~m}$ and the previously estimated jet velocity of $19.8 \mathrm{~m} / \mathrm{s}$, the required $\rho_{\mathrm{m}}$ would be about $60 \mathrm{~kg} / \mathrm{m}^{3}$ implying a water content of the jet on the order of $6 \%$, which seems plausible.

\subsection{Laboratory observations}

A set of carefully designed laboratory experiments (Wright, 2013) was performed to demonstrate that inertial surge was not a necessary requirement for geyser formation. These involved the experimental set-up indicated schematically in Figure 5. A discrete pocket of air was isolated behind a quickopening valve at one end of a pipeline that was otherwise filled with stagnant water maintained at a constant pressure by the presence of a constant head reservoir at the opposite end of the pipeline. The air pocket was maintained at a pressure to match the reservoir head. A vertical riser was installed in the pipeline at a location relatively close to the reservoir. When the isolation valve was suddenly opened (the short-duration pressure fluctuation at about $3 \cdot 3 \mathrm{~s}$ in Figure 6), a large air bubble intruded into the water-filled portion of the pipe. As the air intrusion reached the riser, an event considered to be geyser formation at the small laboratory scale was observed. A pressure trace measured near the bottom of the vertical riser presented in Figure 6 for a typical experiment closely resembles the pressure response for one of the geysers presented in Figure 4. Under certain conditions, the air/water jet formed overtopped a vertical riser nearly $2.5 \mathrm{~m}$ long. More discussion of these experiments is presented below.

\section{Air/water interaction phenomena}

This section deals with the phenomena that involve interactions between large discrete volumes of air and water that have some relevance to the current application. Falvey (1980) provides a detailed discussion of various air-water interactions and some of the topics covered relate to the following discussion.

\subsection{Air intrusions into horizontal pipelines}

When a gas intrudes into a horizontal conduit filled with liquid, such as in the laboratory experiments described in 


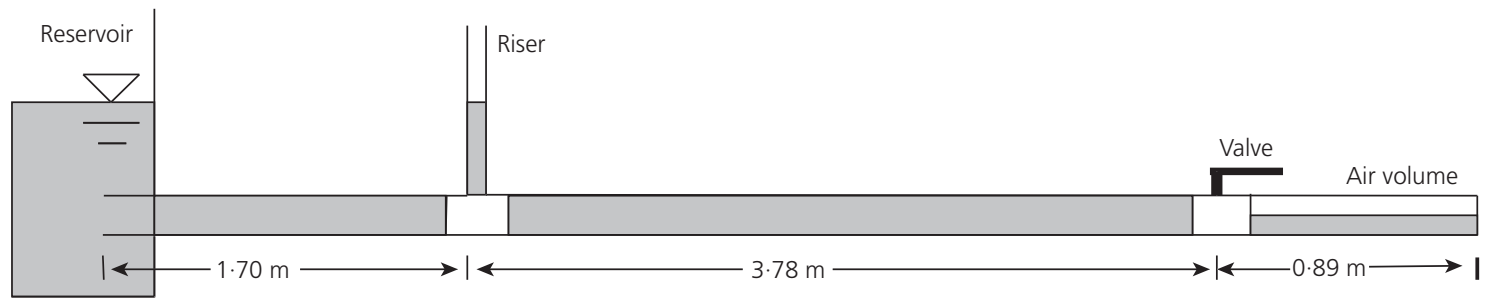

Figure 5. Schematic diagram of the experimental apparatus to observe water displacement in the vertical riser by the escaping air pocket. The pipeline diameter is $9.4 \mathrm{~cm}$

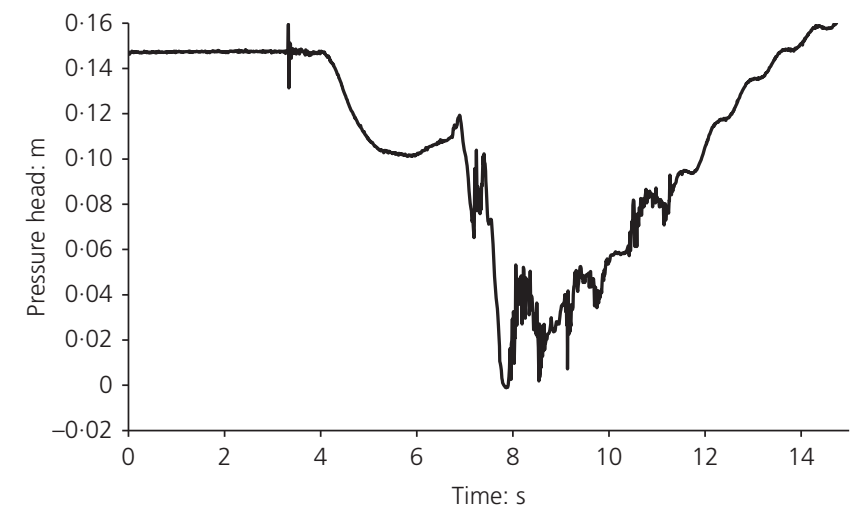

Figure 6. Pressure measurements for a single geyser in laboratory experiment. The riser diameter is $5.1 \mathrm{~cm}$, pipe diameter is $9.4 \mathrm{~cm}$

the previous section, a distinct intrusion front forms as was analysed by Benjamin (1968). A solution for the air intrusion velocity, $U$, into a suddenly opened horizontal water-filled circular conduit is presented in Figure 7. Here $D$ is the conduit diameter and $y$ is the water depth in the flow behind the intrusion head.

The nature of the intrusion is a clearly defined front as depicted in the image in Figure 8. If the flow is not of the zeroenergy dissipation case, the front is followed by a jump-like transition to a greater water depth or smaller air thickness. If the air is continuous, the intrusion thickness remains essentially constant behind the front; however, a finite-volume air intrusion exhibits a trailing tail. Figure 8 indicates an undular bore behind the front. One important implication of this analysis is that a volume of trapped air will move in a certain direction in a flowing conduit depending on the water velocity; that is, the air can move upstream against the flow if the water velocity is less than the intrusion velocity, $U$; Vasconcelos and Wright (2008) demonstrated this by generating flow from a reservoir with a declining head through a pipe with an open downstream end. At high flow velocities, the pipe flowed full

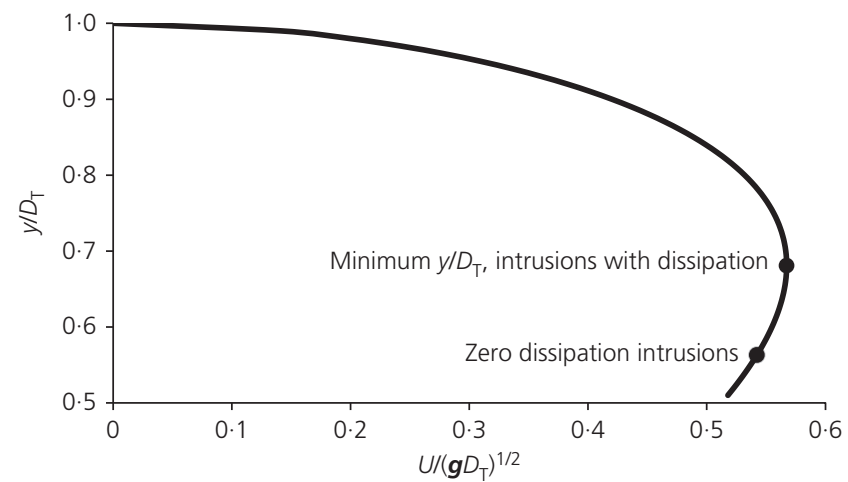

Figure 7. Benjamin solution for air intrusion speed in a circular conduit

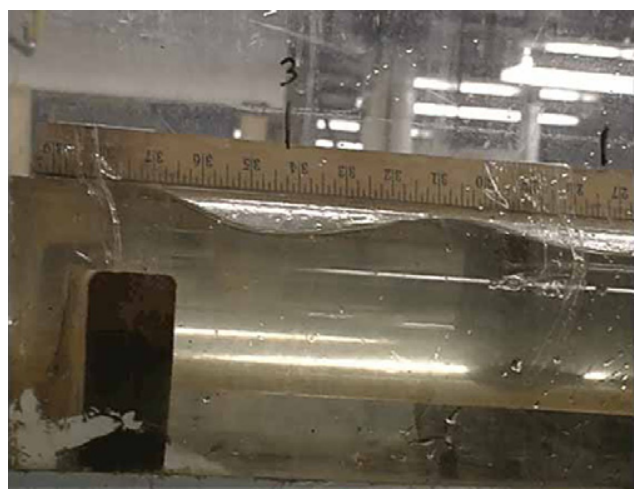

Figure 8. Flow conditions at an air intrusion front in a nearly horizontal conduit

and no intrusion was observed. When the flow velocity through the pipe declined to the intrusion velocity, $U$, an exchange flow was developed in the conduit with a well-defined intrusion front as indicated in Figure 8. The presence of a very small conduit slope will not have a significant 


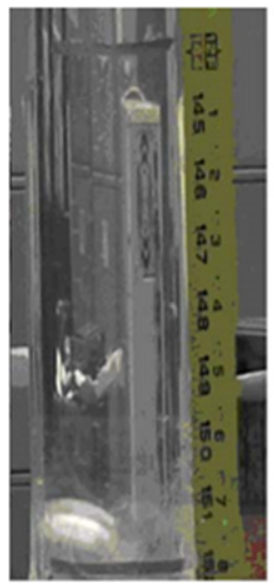

$22 \cdot 31 \mathrm{~s}$

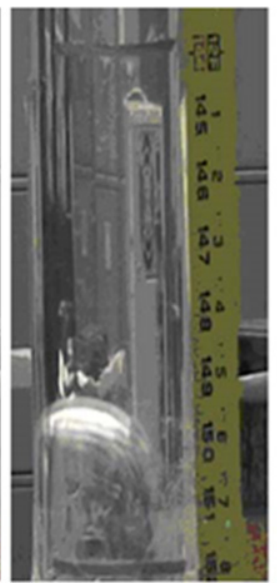

$22 \cdot 45 \mathrm{~s}$

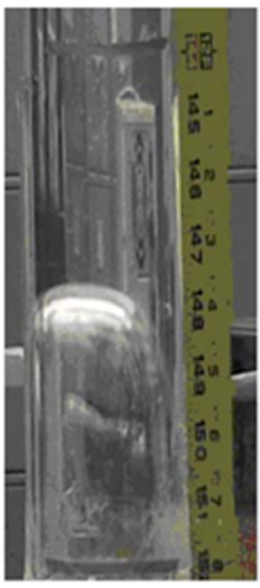

$22 \cdot 58 s$

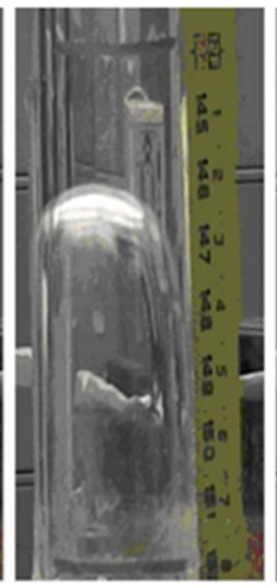

$22 \cdot 71$ s

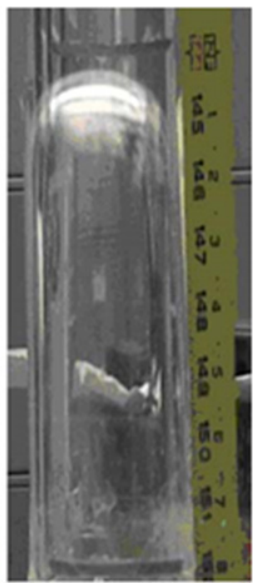

$22 \cdot 85 \mathrm{~s}$

Figure 9. Propagation of an air bubble into a vertical pipe which is partially filled with water and open at the top. The air derives from an intrusion into a water-filled horizontal pipe to which the vertical conduit is attached

impact on the intrusion characteristics and the results above can be generalised. Thus, it is generally possible to determine whether a trapped air volume can move only downstream, or both upstream and downstream thereby spreading out the air. Since $U$ scales as $(g D)^{1 / 2}$, the size of the conduit is extremely relevant; for small-diameter pipes (on the order of a few centimetres), air will generally be forced only in the downstream direction, whereas in large-diameter drainage conduits (on the order of metres), upstream migration of air is to be anticipated in most flow conditions.

\subsection{Air intrusions in vertical conduits}

This phenomenon is referred to as a Taylor bubble, after an analysis by Davies and Taylor (1950). Consider an application with a vertical pipe filled with water, closed at both ends, in which the bottom closure is suddenly removed, similar to the Benjamin condition except in a vertical as opposed to a horizontal conduit. Again, air enters the pipe as water flows out, but, in this instance, the air is not constrained by gravity forces to form a stratified exchange flow. Instead, the air flows upwards through the centre portion of the conduit while water exits downwards as a film flow around the perimeter of the conduit. Figure 9 presents sequential images of air intrusion into a vertical conduit containing water, although the specific conditions do not match the Taylor bubble description. The Taylor bubble propagates upwards at a constant velocity given by $U=0 \cdot 35(g D)^{1 / 2}$ according to Davies and Taylor (1950).

The shear at the interface between the air and water can result in the development and growth of interfacial instabilities, referred to as flooding instability in the two-phase flow literature (e.g. Guedes de Carvalho et al., 2000). At the laboratory scale of Figure 9, no evidence of flooding instability is present. However, since the relative velocity depends on the square root of the diameter, it should be much more likely in the case of field applications such as the nearly $2 \mathrm{~m}$ dia. vertical shaft in Figure 2(a). Preliminary analyses suggest that it may be possible to initiate the flooding instability with a vertical shaft diameter on the order of $0.3 \mathrm{~m}$. Even at that size, dynamic similarity between laboratory-scale investigations and geysering in large drainage systems would not be expected.

Consideration of these various air exchange phenomena leads to a conceptual notion of how geysers could form. A qualitative explanation of how a geyser could occur due to the release of large air pockets is described in this paragraph. A related discussion is presented in the paper by Wright et al. (2011a). Air becomes entrapped within the nearly horizontal conduit during the rapid filling process. Vasconcelos and Wright (2006) discuss several mechanisms by which air can become entrapped in a filling pipeline; laboratory observations indicate that it is a fairly ubiquitous occurrence. Others, including Aimable and Zech (2003) and Li and McCorquodale (1999) discuss other more local phenomena that can also result in air entrapment, although these may be more likely to result in smaller air pockets. A large air pocket propagates along the crown of the conduit as an air intrusion and reaches a vertical shaft where it accelerates upwards due to buoyancy effects. This process is somewhat similar to the Taylor bubble. The absence of a lid on the system results in the upward air flow transferring momentum to the liquid above, causing it to rise ahead of the air 
pocket with a downward leakage of water around the perimeter of the vertical pipe. This phenomenon was observed in the experiments reported by Vasconcelos and Wright (2011). However, since the volume of water in the surcharged manhole is apparently fairly small according to the pressures indicated in Figure 3, it is expected that the water cap above the air can be lost before the upward flow reaches the top of the manhole and the air escapes upwards. On the basis of the rise height of the water jet in Figure 2(a), for example (assumed to be roughly equal to the velocity head in the manhole), it appears that the rising air column will trigger the onset of flooding instability where the high-velocity shear between the rising air and falling water generates instabilities. The large vertical air velocity then entrains water droplets and carries them upwards to form the observed geyser. This phenomenon was not observed in the small-scale experiments by Vasconcelos and Wright (2011) since the velocity of the rising air bubble does not reach the magnitude suggested by Guedes de Carvalho et al. (2000) to produce flooding instability and the air-water interface along the rising bubble remains smooth. The duration of observed geysers in the videos (often exceeding $30 \mathrm{~s}$ ) clearly indicates that the liquid in the geyser should come from more than just that in the vertical shaft, and it is probable that interfacial instabilities in the horizontal flow, commonly called slug flow, also contribute to the geyser phenomenon in order for high-velocity flows to last for nearly a minute. However, individual slugs of air in a slug flow should not permit a geyser lasting anywhere close to $30 \mathrm{~s}$. Another possibility is that the vertical shaft is a dropshaft with water falling down from near-surface conduits and is blown back upwards by the rising air; lack of detailed information from the many geyser videos that the authors have viewed does not allow a definite conclusion. This explanation for geysers suggests that air pockets with quite large volumes (on the order of tens or hundreds of cubic metres) would be required to generate the observed geysers. Subsequent discussion will address how air pockets of this size could be formed.

\subsection{Pressure rises due to air compression}

An additional topic involves how pressure rises sufficiently large to damage structures could be generated in the presence of trapped air pockets. Although this is not explicitly linked to the geyser phenomenon, reports of structural damage in sewer systems imply the presence of significant pressures but may well be associated with completely different events. A significant study is that of Martin (1976) who analysed a different but related problem. In that numerical study, the configuration considered was a pipeline initially isolated from a constant head reservoir by a valve as indicated in the sketch in Figure 10 with a volume of air, $V_{\text {air }}$, located at the downstream, higher elevation end. This air was assumed initially to be at atmospheric pressure. When the valve is suddenly

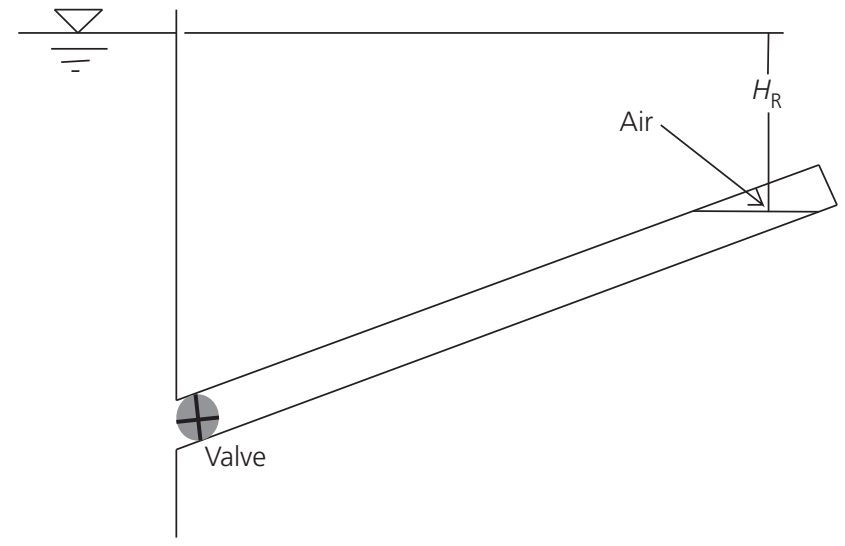

Figure 10. Schematic diagram of system analysed by Martin (1976). The particular sketch indicates a closed end at the downstream end of the pipe

opened, the pressure difference between the reservoir and the pipeline initiates a flow into the pipe, which must pressurise and compress the air since the water is assumed to be incompressible. The inertia of the inflow is sufficient to induce a pressure oscillation which is mathematically predicted using an inertial surge model for the water flow, geometric relations connecting the water velocity and the rate of air compression and thermodynamic relations describing the compression process (e.g. assuming the air compression and expansion is adiabatic). The equations assume that the air volume is trapped in a length $V_{\text {air }} / t$ (with $t$ being the cross-sectional area of the pipe) at the downstream end. This is not strictly valid unless the pipe is vertically oriented but would not likely be a poor approximation if the pipe slope is significant. It is unlikely that such an approximation would be valid for large air volumes in a conduit with small slope since the air could potentially be spread over long distances at the pipe crown. Figure 11 includes simulation results for two sets of conditions that differ only by the initial volume of air. The inertial surge into the pipeline upon valve opening is followed by pressure increases considerably greater than the steady-state reservoir pressure head. It is also seen that small air volumes result in larger pressure increases.

Martin's (1976) analysis has subsequently been adapted to analyse pressures in drainage systems (e.g. Zhou et al., 2002a). In that particular analysis, there is a ventilation location at the downstream end of the system which allows air to escape as through an orifice, a condition that was also analysed by Martin (1976). However, there are doubts regarding the applicability of this analysis to drainage system dynamics. Effectively, the inertial surge analysis assumes that the conduit fills with a vertical front - that is, the flow state passes from 


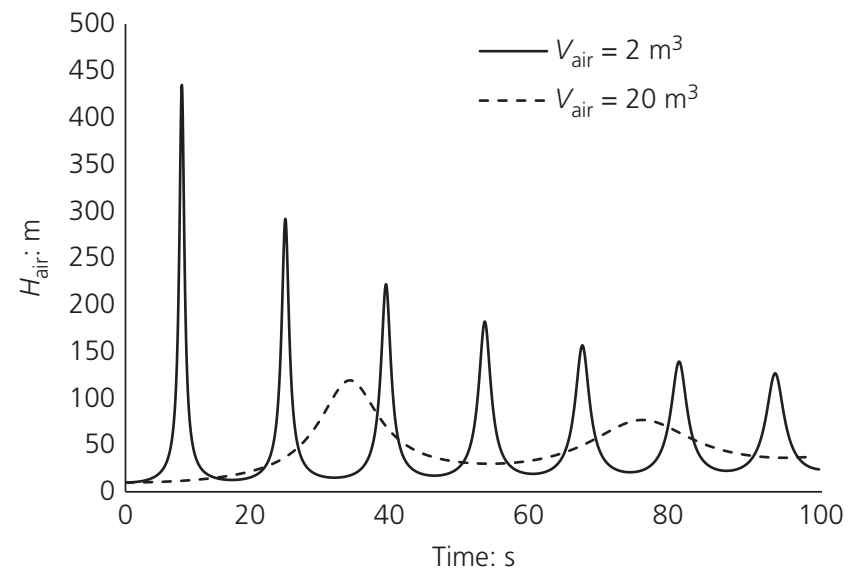

Figure 11. Analysis for pressure in the trapped air pocket for air volumes of 2 and $20 \mathrm{~m}^{3}\left(D=05 \mathrm{~m}, H_{\mathrm{R}}=50 \mathrm{~m}\right.$, total length $=1000 \mathrm{~m}, f=0.02$ ).

empty to surcharged over a very short flow length. This approach has been used by others and verified with flow in pipes with a diameter on the order of $1 \mathrm{~cm}$. In the discussion above for air intrusion into nearly horizontal pipelines, it was seen that the air intrusion velocity would be an order of magnitude greater for a $1 \mathrm{~m}$ dia. pipeline than for a pipeline of $1 \mathrm{~cm}$ dia. In larger-diameter drainage systems, the air would not simply be compressed at the end of the conduit, but would intrude along the pipe crown above the entering flow which would substantially alter the surge dynamics and make any predictions or experimental observations in small-diameter pipes dubious in terms of applicability to large-diameter systems. Guizani et al. (2006) have shown that the approximation of a vertical front is poor, even in laboratory studies with a conduit diameter of $\sim 10 \mathrm{~cm}$. Even though Zhou et al. (2002a) have applied their analysis to large-diameter sewer lines, they performed laboratory experiments (Zhou et al., $2002 b$ ) in a set-up with a small diameter and also applied pressure differentials of up to $50 \mathrm{~atm}$, which would certainly not be expected in a sewer system. Even under those conditions, they noted that the air-water flow exhibited a degree of stratification and therefore did not conform to the assumption of a sharp interface perpendicular to the pipeline. The tendency for trapped air to stratify and flow along the top of the conduit should be an important aspect of transient flow in large-diameter sewers.

\section{Laboratory investigations}

\subsection{Geyser experiments}

A set of laboratory experiments (Wright, 2013) was performed to demonstrate that inertial surge was not a necessary requirement for geyser formation. These involved the experimental

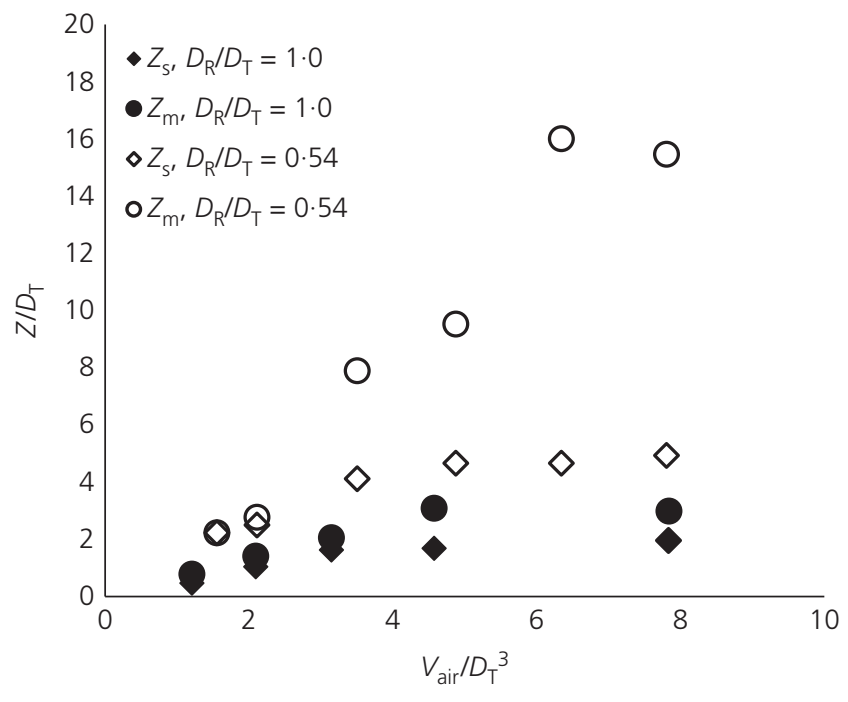

Figure 12. Rise heights for two different riser diameters (riser diameter/tunnel diameter of 0.54 and 1.0) as a function of air pocket volume

set-up indicated schematically in Figure 5 and described briefly above. As discussed previously, a vertical riser was installed in the pipeline relatively close to the reservoir end and the riser diameter was a key control variable in the experiments along with the air volume. As the released air pocket reached the vertical riser, it began to intrude vertically as in Figure 9. As the riser height was relatively large, the vertical rise was contained within the riser except for a few extreme cases. Video recordings of the rising air were made. Two distinct phenomena could be observed. At some point, the rising air rose through the water initially standing in the vertical shaft providing a free path for air escape. This is referred to as 'breakthrough' and labelled as $Z_{\mathrm{s}}$ in Figure 12 and represents the vertical displacement of the water surface relative to its initial level before air release. As the air forced the water upwards and broke through the interface, it lifted some water above that location with an observed splash. The maximum vertical extent of the water is referred to as $Z_{\mathrm{m}}$ in the same figure. If the riser diameter was nearly the same size as the horizontal conduit, the water level in the riser scarcely changed from its original level and there was essentially no splash. In other cases with the riser diameter much smaller than the horizontal pipe diameter, the rising air is capable of lifting water distances significantly greater than the reservoir head as depicted in Figure 12 with considerable splash. This is interpreted to be the small-scale equivalent of the geyser. Figure 12 shows the effect of increasing air pocket volume; rise heights increase with air volume up to some limit after which the air volume is sufficiently large that it no longer affects the rise in the vertical shaft. Figure 13 presents the results over a range of 


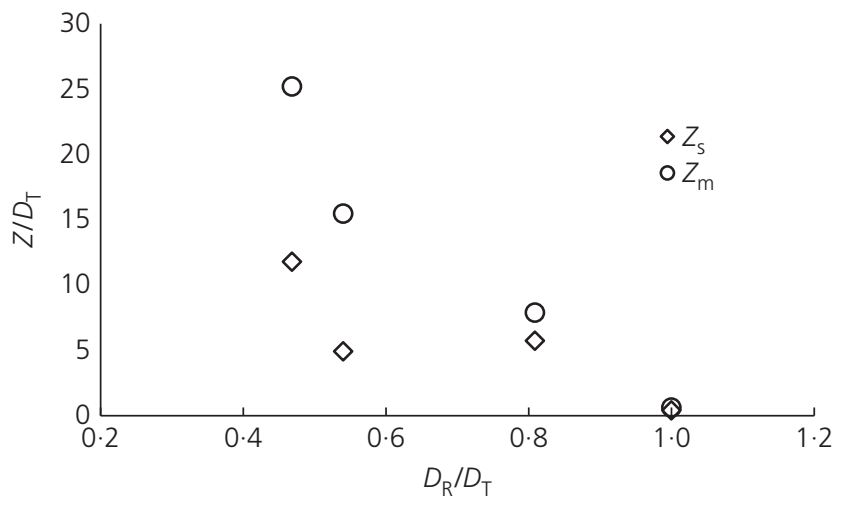

Figure 13. Rise heights for large air volumes as a function of relative riser diameter

the ratio of the riser to pipe diameter, showing the strong effect of riser diameter. These results suggest that geysers can be significantly controlled by designing sewer systems with vertical shafts on the order of the conduit diameter or larger and this guidance has already been incorporated into the design of CSO tunnel systems in Washington, DC, USA and London, UK.

\subsection{Flow regime transitions}

A brief discussion (also presented in the paper by Wright et al. (2006) along with experimental data) of how large air volumes can come to be entrapped is appropriate, although laboratory experience indicates that there are myriad processes that can lead to air pocket entrapment (Vasconcelos and Wright, 2006). It is presumed that a storage tunnel is filled from the upstream end of a downward-sloping pipe with small grade. At low inflow rates, the tunnel could fill essentially as a bathtub, starting at the low end. At larger flow rates, the conduit generally initially goes full at the downstream end and a filling front in the form of a hydraulic bore begins to propagate upstream such as indicated in Figure 1. Wright et al. (2006) have performed experiments initiating an inflow into a pipe closed at the downstream end with a small downward slope. The inflow reflected off the closed end and produced a hydraulic bore that began to propagate upstream against the inflow. At large inflow rates, the hydraulic bore completely fills the crosssection resulting in what is referred to as a pipe-filling bore, as indicated in the measurements presented in Figure 14. Bottom pressures were measured at two locations along the pipe and the history of the inflow plus the returning bore are evident in the figure. The bore propagates upstream with a relatively high speed. At lower filling rates, the condition in Figure 15 develops where the bore is of the ordinary free surface type - that is, not surcharged on the downstream side. A long gradual transition to the pipe crown can then occur. The primary difference between these two figures is the inflow rate which

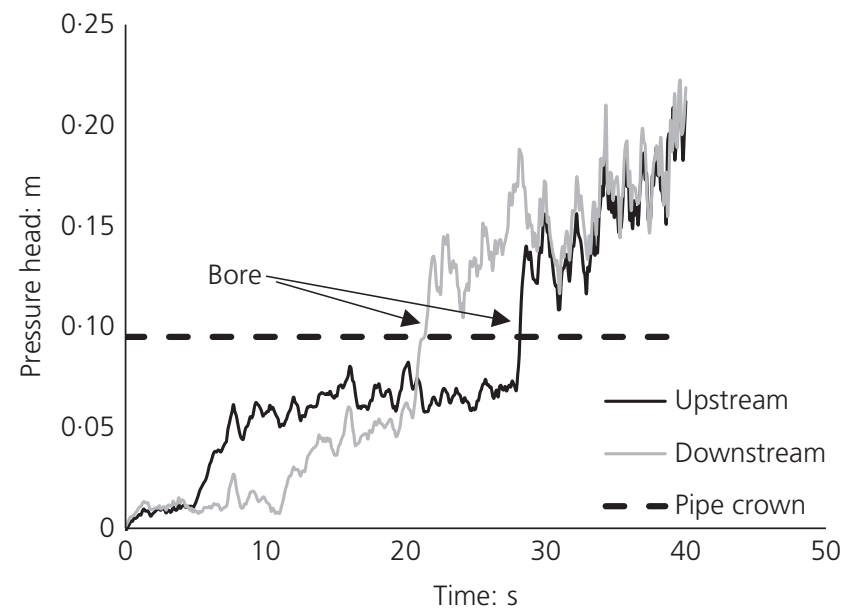

Figure 14. Measurement of flow depth at two locations for conditions with a pipe-filling bore $\left(Q=0.00234 \mathrm{~m}^{3} / \mathrm{s}\right)$

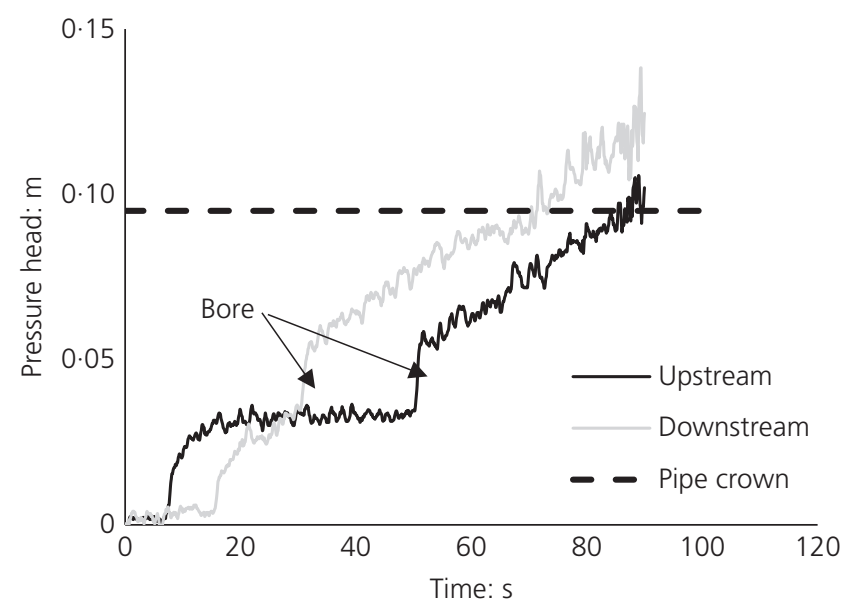

Figure 15. Measurement of flow depth for a free surface bore followed by a gradual flow regime transition $\left(Q=0.000844 \mathrm{~m}^{3} / \mathrm{s}\right)$

was substantially higher in Figure 14. In actual applications, the presence of friction over long lengths of pipe and with distributed inflows and storage in side tunnels, the bore (even if initially pipe filling) is likely to decrease in strength as it moves upstream, often establishing a free surface bore with a long gradual flow regime transition. If a free surface bore encounters some upstream transition such as a sudden grade change through a vertical drop or a diameter change, the bore will send a reflection back down the conduit with an increase in water depth. This increase can surcharge the flow at the reflection point, creating a long surface above the gradual flow regime transition with trapped air. This distance could potentially be kilometres in length with a large volume of air. In 
actual systems, there are often intermediate ventilation points that allow some of the air to escape, but once the bore passes the last ventilation point the trapped air must be compressed by the advancing bore.

\section{Numerical modelling}

\subsection{Modelling requirements}

The preceding discussions that describe various air/water interactions clearly indicate that a three-dimensional computational fluid dynamics (CFD) approach will be necessary to resolve the details of the complex stratified flow phenomena. However, it is infeasible at the present time to implement a complete CFD solution to stratified two-phase flow in a large-scale tunnel system some tens of kilometres long and several metres in diameter. It seems necessary to model the flow in the nearly horizontal conduits as a one-dimensional flow with the potential to couple with a CFD approach in the vicinity of a vertical shaft where a geyser might occur. Even one-dimensional models will require a fair level of sophistication. A two-phase flow model would be required to simulate the presence and motion of trapped air pockets as opposed to a homogeneous mixture of air and water. Currently, most models for application to design of CSO systems do not have this capability and only model the water phase. A minimal computational framework would require simultaneous computation of both free surface and pressurised flow within adjacent portions of the conduit and most previous models applied to this application are of that type. Different computational approaches are possible as described in more detail in the next sections. The significant issue is that the transition between the two flow states must be handled appropriately. As discussed above, the transition between flow states may occur as a moving hydraulic bore and thus a numerical scheme that can adequately handle the occurrence of shocks (bores) is necessary. Additional bores that may not involve flow regime transition as described in the previous section may be present and must also be adequately resolved. The next section describes the potential approaches that can meet these objectives.

\subsection{Model frameworks}

Bousso et al. (2013) provide a review of numerical modelling techniques. Two basic approaches can be applied to model mixed flow with a portion of the conduit may be flowing with a free surface and the remainder in a pressurised state. A different set of governing equations is required for each of these flow regimes. In the free surface flow regime, the St Venant equations are generally applied for the description of a one-dimensional flow while, in the pressurised regime, the flow can be modelled as incompressible or compressible. Compressible flow equations for one-dimensional pressurised flow are generally referred to as water hammer equations. It should be noted that if air is present to a significant extent in an application, water hammer itself is unlikely to have a significant impact on the problem; however, coupling the two flow regimes can be handled more logically by utilising the water hammer equations. General solution approaches may generally be categorised as shock-fitting or shockcapturing methods.

\subsubsection{Shock-fitting techniques}

This approach generally considers the flow regime transition between free surface and pressurised flow to occur through a hydraulic bore, although this actually need not be the case. The bore is treated as a discontinuity or 'shock' for which the location varies with time. The St Venant equations are applied on the free surface side of the shock, while water hammer equations are typically applied on the pressurised side of the shock. An example of this type of application is the solution by Cardle and Song (1988), which was implemented as a numerical code called MXTRAN. For years, MXTRAN was the only general model that was available for application to this mixed flow problem in rapidly filling sewers. The solution technique is relatively straightforward if it is considered that there is only one shock that results in flow regime transition. In MXTRAN, the pressurised portion of the flow was solved by the method of characteristics (MOC) (e.g. Wylie and Streeter, 1982). MOC is an explicit numerical scheme and the Courant condition specifies a maximum allowable time step for numerical stability. This time step is generally much more limiting than a corresponding time step for an explicit scheme applied to the free surface portion of the flow, so the St Venant equations can be solved on the same time step as well although the results may not necessarily be highly accurate. The shock is treated as a moving boundary condition. There are five variables that must be computed: the depth (or area) and the velocity (or discharge) on either side of the bore and the bore propagation speed. Mass and momentum equations across the bore are written, and in the MOC framework, $\mathrm{C}^{+}$equations are written on both sides of the bore and the $\mathrm{C}^{-}$equation on the subcritical (pressurised) side of the advancing bore; from these the bore speed can be computed and the location of the bore front can be updated over a computational time step. The details of the solution procedure are not provided here but several references (e.g. Leon et al., 2006; Politano et al., 2007) deal with the application. Although the procedure is straightforward, there are cases of flow regime transition that do not satisfy the pipe-filling bore transition condition. Notably, these are the gradual flow regime transition with free surface bore as discussed above and the transition back to a free surface state from a pressurised one that may occur later in a transient event. This latter transition can occur as an air intrusion depending on the relative speed of air and water flows. These situations can be subject to special 
treatment so that a general numerical solution can be implemented.

Solution constraints become more severe when the typical condition of an urban drainage system with multiple inflow points is considered. Under those circumstances, the possibility exists for multiple bores that have the ability to interact with each other, making the front tracking implementation impossible to implement in a general manner. Even the relatively straightforward system indicated in Figure 1 where a moving bore will interact with the stationary hydraulic jump at the slope change requires a special handling of the conditions at that location. It was also discussed above that a pipe-filling bore will often transition back to a free surface bore with gradual flow regime transition due to various effects. In the MXTRAN implementation, it is explicitly assumed that once a pipe-filling bore forms, it cannot transition back to a free surface bore state. In a review of results from MXTRAN simulations, it has been observed that large negative pressures behind the bore front were predicted due to this unphysical constraint on the numerical formulation.

\subsubsection{Shock-capturing techniques}

The inherent limitations of shock-fitting techniques have led many modellers to develop alternative approaches that are best described as shock-capturing schemes. The most familiar example is a method by Cunge and Wegner (1964), Preissmann (1960) and others that is generally referred to as the Preissmann slot technique. Note that this is only a mathematical artefact and has no physical basis. The fundamental consideration is that both the St Venant and the water hammer equations are representations of mass and momentum conservation, and both admit the possibility of shock or wavelike disturbances. The disturbance in the case of the St Venant equations is the free surface hydraulic bore described above while an acoustic or pressure wave represents the disturbance in the water hammer equations. The Preissmann slot allows for the two wave speeds to correspond to each other when the conduit is surcharged. The Preissmann scheme generally considers a circular conduit with a relatively narrow, infinitely high 'hypothetical' slot at the top allowing for free surface flow to be considered even under surcharge conditions. Since the free surface elementary wave speed is given by $c=(g A / T)^{1 / 2}$, a judicious choice of the top width, $T$, would allow for a wave speed approximating the acoustic wave speed in pressurised flow and the St Venant equations can, in principle, be applied in pressurised flow. In the formulation by Cunge, this concept was not explicitly stated and the slot width was not necessarily selected to be that required to give the correct acoustic wave speed (recall the assertion above that water hammer is not likely to be relevant in drainage systems with significant air), but rather the choice of $T$ was made with the context of providing a computationally expedient time step. The numerical technique implemented by Cunge and Wegner (1964) was an implicit scheme, so there was no Courant condition requirement to be satisfied. However, numerical accuracy considerations still require that numerical Courant numbers be on the order of one.

There are several issues associated with the implementation that require modifications to the scheme. A major one is that subatmospheric pressures can exist in a pressurised pipe flow. The Preissmann slot scheme as described would result in the re-establishment of free surface flow if a subatmospheric pressure were to be predicted, regardless of whether or not there is a source of ventilation to admit the inflow of air required to establish a free surface flow. A more practical solution consideration occurs with the selection of the slot width, T. Slot widths much larger than required to represent the correct acoustic wave speed are often utilised. If water hammer is not an important phenomenon, then this choice does not result in a significant defect in the model. However, if the slot width is so large that the flow area in the (fictitious) slot approaches the flow area in the actual cross-section, then continuity is not correctly preserved in the model and errors develop in the numerical solution.

An alternative to the Preissmann slot has been developed more recently, referred to as the two-component pressure approach (TPA). This method is also a mathematical artefact as opposed to a true description of the flow system. The fundamental details of the TPA are given in the paper by Vasconcelos et al. (2006) and an overview of the method is discussed here. If the pressurised flow acoustic wave speed were modelled in an alternative way, then a similar numerical outcome would result. In the TPA model, the acoustic wave speed is achieved conceptually by considering the conduit wall to have a specified elasticity but the water is considered as incompressible to simplify the equations. In real systems, the acoustic wave speed is well known to be a function of water compressibility, pipe wall elasticity and free air bubbles entrained in the flow (Wylie and Streeter, 1982); in the TPA, all of these effects are represented by the elasticity of the pipe wall. The pressure term in the St Venant equations is further considered to consist of two components, one associated with the hydrostatic pressure within the actual cross-sectional flow area of the conduit plus a surcharge pressure if the flow is pressurised. By decomposing the pressure into these two terms, the St Venant equations can be shown to correspond to water hammer equations and an implementation similar to the Preissmann slot approach can be developed. There are some practical advantages but also limitations with the TPA method. One advantage is that subatmospheric pressures can be included more flexibly in this method; all that is necessary is to keep track of the surrounding nodes and determine whether a source of air is present to 
Air-water interactions in urban

drainage systems

Wright, Vasconcelos and Lewis re-establish a free surface flow or whether a negative pressure would be experienced. An issue similar to the Preissmann slot method is that the pipe wall elasticity can arbitrarily be adjusted to provide any desired acoustic wave speed and there are computational advantages to using as low a one as feasible. The actual acoustic velocity in a drainage network is an open question since the presence of entrained air bubbles, which would be expected to be present in a system with drop structures, can reduce the acoustic wave speed down to as low as $100 \mathrm{~m} / \mathrm{s}$ (Wylie and Streeter, 1982) at relatively low air fractions. Nevertheless, if the acoustic wave speed is set at some very low value such as $50 \mathrm{~m} / \mathrm{s}$ in order to accrue computational advantages, the pipe wall expansion under typical transients can create continuity errors due to the change in computed pipe diameter. Numerical experiments have suggested that so long as acoustic wave speeds on the order of $250 \mathrm{~m} / \mathrm{s}$ or more are used, continuity errors due to this effect are minimal.

The numerical scheme is a finite-volume method implementing Roe's first-order upwind scheme; others have extended this to higher order accuracy methods. This numerical scheme is good at numerically capturing shocks (bores) but numerical oscillations develop in the vicinity of the bore front. Methods have been proposed to deal with the oscillations if desired (Vasconcelos et al., 2009). The model has been verified against a variety of experimental data and numerical predictions using other less general methods (Vasconcelos and Wright, 2007b). For implementation in an actual drainage network, it is necessary to handle each drop shaft as a boundary condition with some specification of the inflow derived from a consideration of input from the overlying sewer system. Applications have been made to support the design of several CSO storage tunnel systems including the one currently under construction in Washington, DC (Lautenbach et al., 2008) and the proposed Thames Tideway Tunnel system in London, UK. Application to these actual systems has also contributed to an understanding of additional processes relevant to tunnel filling conditions; the next section provides additional discussion on these issues.

\subsection{Applications}

It should be apparent that air is not explicitly included in the numerical formulation discussed above since all the methods discussed only solve single-phase (water) equations. However, the model implementation may provide some insights into air processes in drainage systems. For example, if a pipe-filling bore develops, air will be expelled ahead of the advancing bore front through available ventilation point(s). If the ventilation is adequate, then the air will not be significantly compressed and the model predictions can be used directly. If the ventilation is more limited, the situation becomes more complex. In general, air becomes pressurised as it is forced out through a limited ventilation area, usually approximated numerically as an orifice. The increase in air pressure in turn slows down the bore propagation and if it is slowed down sufficiently then the pipe-filling bore is arrested in a manner where an air intrusion is generated at the pipe crown, implying that the original pipefilling bore becomes a free surface bore. Such a condition was analysed by Vasconcelos and Wright (2009) and TPA modifications allowing the air phase to compress were implemented and shown to predict well the key observed features of experiments including the generation of motion in the fluid ahead of the advancing bore (termed pre-bore motion) and the degeneration of the pipe-filling bore into a free surface bore (termed interface breakdown).

The previous discussion described the physical processes by which discrete pockets of air could be trapped in a filling flow. In general, these events involved the propagation of a bore front and its interactions with specific elements in a drainage system such as a grade change, a diameter change, a side tunnel or a large-diameter vertical shaft. Under these and probably other circumstances, the air in a well-ventilated system will be at atmospheric pressure before the entrapment process and therefore does not pressurise as described in the previous paragraph. Therefore, it is reasonable to expect that the TPA method, capable of accurately simulating bore motion, can predict the location and volume of air volumes when the entrapment process occurs. Of course, the model cannot reasonably predict any subsequent behaviour of the air pocket since air is not explicitly included in the basic TPA formulation. What ensues in the model predictions is therefore physically unrealistic. In general, the computational outcome is as follows.

- The TPA method predicts the location and volume of entrapped air, but in the model, this is interpreted as a void since air is not explicitly included in the basic formulation.

- As the simulation proceeds, the bore advancement generally fills the void with no compression of the neglected air included in the analysis to slow down the inertia of the bore.

- When the void completely vanishes, the two columns of water on either side of the void collide, creating a simulated water hammer event that does not actually occur in that manner due to the presence of trapped air.

- The computed void collapse results in water hammer pressures in which the magnitude of the transient pressure depends directly on the assigned acoustic wave speed. The magnitude of pressure fluctuations also depends on the initial void volume, with larger volumes creating larger pressure rises (although the water flow conditions also influence this magnitude). 
- In the physical system, there is air present in that void space and air would be compressed in order to stop the inertia of the flow. However, there are two important differences between what happens in this case and the numerical model predictions. First, the pressure rise does not actually depend on the acoustic wave since the air compression is basically an inertial surge problem as discussed previously. Second, the pressure transients will be greater for small air volumes rather than large ones for reasons also discussed previously and indicated in Figure 11.

As a result of these fundamental differences between the simulated system and the actual system, the pressure predictions by the TPA model are different such that it is not possible to conclude that the predicted pressures are conservative (too large) or the opposite case; in fact, it is probable that either outcome is possible depending on the initial air pocket volume.

\subsection{System pressure considerations}

Given the description in the previous section and due to the fact that there has apparently been no research on pressure changes in air volumes compressed by hydraulic bores, a limited experimental investigation was conducted to study this issue in a simplified system. Some preliminary experiments were performed in order to understand the nature of pressure fluctuations due to compression of an entrapped pocket of air by an advancing hydraulic bore (Wright et al., 2013). These experiments were somewhat artificial in order to provide a straightforward experiment and involved an isolation valve at the entrance of a pipeline connected to a constant head reservoir; this valve was normally closed. At a location towards the opposite end of the pipeline, a ventilation riser was installed with a normally open valve located at its base. Upon the sudden opening of the reservoir, a pipe-filling bore propagated into the partially filled pipe, pushing the air ahead of it. As the bore advanced down the pipeline, the riser valve was suddenly closed, trapping a volume of air ahead of the advancing bore. Wright et al. (2013) present the results including the effect of several variables and show that significant pressure variations (both high and low pressures) due to air compression are experienced and, similar to the results in Figure 11, smaller trapped air pockets result in larger pressure variations. It is not totally clear how to scale the results to prototype applications, but a scaling law was proposed that fitted the available data reasonably well.

The TPA method was modified to account approximately for this trapped air volume (Vasconcelos et al., 2015). The conventional model was used to determine the location and volume of the void which was then assumed to be filled with air at atmospheric pressure. This air pocket was assumed to be of constant thickness related to the volume and length of the computed void. This location was treated as an internal boundary condition and modelled as a compressible, polytropic gas that conserved the gas mass. A comparison (Wright et al., 2016) of this modified TPA model with the original indicated that pressure oscillations for simulations in the proposed Thames Tideway Tunnel system were somewhat less severe than the original TPA predictions without air compression although this conclusion is dependent to some extent on the assumed value for the acoustic wave speed.

\section{Considerations for future study}

This manuscript presents the results of a number of separate investigations that serve to advance knowledge of air-water interactions in urban drainage systems. At present, it is believed that there is a good understanding that the cause of at least some sewer geysers is associated with the release of large pockets of entrapped air through ventilation or other vertical shafts that exist in a surcharged state at the time of air release, without significant system pressures developing. However, there are several outstanding issues that require further study including the following.

- Additional measurements (at least pressures and geometric details) of the conditions within a filling tunnel system experiencing geysers would be helpful to better understand the conditions leading to geyser formation. It is suspected that there may be multiple conditions that lead to geyser formation and that a single explanation may not be sufficient. In particular, an understanding of the role of water spilling down a vertical shaft during air release through that shaft may be critical.

- Computational fluid dynamics models could be useful in shedding additional light on specific processes such as air pocket release at a riser, onset of interfacial instabilities along the surface of a tunnel filling flow and so on.

- It would be helpful to demonstrate that the proposed description is at least one process by which geysers occur. Ideally, it would be possible to obtain measurements in a large-scale drainage system so that the scale effects in small-scale laboratory systems do not confound the interpretation of the observations. However, preliminary analysis suggests that flooding instabilities should be capable of being generated in some moderately large-scale laboratory studies.

- Additional study is warranted on conditions that may result in large positive or negative pressures due to compression of entrapped air in a system. There are several observations of structural damage, often at high points in drainage systems, for which a plausible explanation is that air at that location was trapped by a filling front and 
compressed by the filling process. A better understanding of the conditions during which severe pressure transients could occur would be helpful.

- The TPA model appears to be quite robust in modelling single-phase (water) flow in rapidly filling systems. Additional effort in incorporating large entrapped air pockets into the general model formulation appears promising without requiring the formulation of a complete two-phase flow model. This may require an additional component that tracks the migration of air within a filling drainage system. This type of model should realistically represent the behaviour of large air pockets spreading along the crown of drainage conduits.

- Additional investigation on passive methods for geyser control could prove useful for engineering design. Several approaches have been investigated, but the difficulty is that drainage tunnels generally fill in an uncontrolled manner and it seems difficult to control all possible filling scenarios. So far, the only method that appears to provide positive geyser control is to construct ventilation shafts with a cross-sectional area at least two-thirds of the main conduit area. This is supported by small-scale laboratory studies but should be confirmed in larger-scale systems. Moreover, the required area ratio was rationalised on the basis of some simplified arguments (Wright, 2013) but should be more rigorously verified.

\section{Acknowledgements}

The impetus for this manuscript was a presentation by the first author at the Gerhard Jirka Summer School, sponsored by IAHR at Hong Kong University of Science and Technology in December 2014.

\section{REFERENCES}

Aimable R and Zech Y (2003) Experimental results on transient and intermittent flows in a sewer pipe model. In 30th IAHR Congress Proceedings, Thessaloniki, Greece: Water Engineering and Research in a Learning Society, Modern Developments and Traditional Concepts (Ganoulis $\mathbf{J}$ and Prinos P (eds)). International Association for Hydro-Environment Engineering and Research (IAHR), Madrid, Spain, vol. B, pp. 377-384.

Benjamin TB (1968) Gravity currents and related phenomena. Journal of Fluid Mechanics 31(2): 209-248.

Bousso S, Daynou M and Fuamba M (2013) Numerical modeling of mixed flows in storm water systems: critical review of literature. Journal of Hydraulic Engineering 138(10): 385-396.

Cardle JA and Song CSS (1988) Mathematical modeling of unsteady flow in storm sewers. International Journal of Engineering Fluid Mechanics 1(4): 495-518.

Cunge JA and Wegner M (1964) Numerical integration of Barre de Saint-Venant's flow equations by means of an implicit scheme of finite differences. Applications in the case of alternately free and pressurised flow in a tunnel. La Houille Blanche 1: 33-39 (in French).

Davies RM and Taylor GI (1950) The mechanics of large bubbles rising through extended liquids and through liquids in vertical tubes filled with water. Proceedings Royal Society of London, A 200(1062): 375-390.

Falvey HT (1980) Air Water Flow in Hydraulic Structures. US Government Printing Office, Denver, CO, USA, US Department of Interior, Water Resources Technical Publication, Engineering Monograph 41.

Guedes de Carvalho JRF, Talaia MAR and Ferreira MJF (2000) Flooding instability of high-density gas slugs rising in vertical tubes filled with water. Chemical Engineering Science 55(18): 3785-3802.

Guizani M, Vasconcelos JG, Wright SJ and Maalel K (2006) Investigation of rapid filling of empty pipes. CHI Journal of Water Management Modeling, http://dx.doi.org/10.14796/JWMM.R225-20.

Guo Q (1989) Geysering in urban storm drainage systems. In 23rd IAHR Congress Proceedings. International Association for Hydro-Environment Engineering and Research (IAHR), Madrid, Spain, pp. S75-S81.

Guo Q and Song CSS (1990) Surging in urban storm drainage systems. Journal of Hydraulic Engineering 116(12): 1523-1537.

Lautenbach DJ, Vasconcelos JG, Wright SJ et al. (2008) Analysis of transient surge in the proposed District of Columbia water and sewer authority deep tunnel system. In Proceedings of the Water Environment Federation Collection Systems 2008. Water Environment Federation, Alexandria, VA, USA, pp. 442-468.

Leon AS, Ghidaoui MS, Schmidt AR and Garcia MH (2006) Godunov-type solutions for transient flow in sewers. Journal of Hydraulic Engineering 132(8): 800-813.

Li J and McCorquodale A (1999) Modeling mixed flow in storm sewers. Journal of Hydraulic Engineering 125(11): 1170-1180.

Liou CP and Hunt WA (1996) Filling of pipelines with undulating elevation profiles. Journal of Hydraulic Engineering 122(10): 534-539.

Martin CS (1976) Entrapped air in pipelines. In Proceedings of the 2nd International Conference on Pressure Surges. British Hydromechanics Research Association, Bedfordshire, UK, pp. 15-28.

Nielsen KD and Davis AL (2009) Air migration analysis of the Terror Lake Tunnel. In 33rd IAHR Congress 2009. International Association for Hydro-Environment Engineering and Research (IAHR), Madrid, Spain, pp. 262-268.

Politano M, Odgaard AJ and Klecan W (2007) Case study: numerical evaluation of hydraulic transients in a combined sewer overflow tunnel system. Journal of Hydraulic Engineering 133(10): 1103-1110.

Preissmann A (1960) Propagation des intumescences dans les canaux et les rivières. Proceedings of 1st Congress of the French Association for Computation (AFCALTI), Grenoble, France, pp. 433-442 (in French).

US EPA (United States Environmental Protection Agency) (1972) https://www.epa.gov/laws-regulations/history-clean-water-act (accessed 08/08/2017).

US EPA (2015) http://www.epa.gov/sites/production/files/201510/documents/csosso_rtc_factsheet.pdf (accessed 11/08/2017).

Vasconcelos JG and Wright SJ (2006) Mechanisms for air pocket entrapment in stormwater storage tunnels. In World Environmental and Water Resource Congress 2006: Examining the Confluence of Environmental and Water Concerns (Graham R (ed.)). ASCE, Reston, VA, USA, paper 40856-14275 (CD-ROM).

Vasconcelos JG and Wright SJ (2007a) Experimental investigation on surcharging of flowing sewers. CHI Journal of Water Management Modelling, http://dx.doi.org/10.14796/JWMM.R227-10.

Vasconcelos JG and Wright SJ (2007b) Comparison between the two-component pressure approach and current transient flow solvers. Journal of Hydraulic Research 45(2): 178-187. 
Vasconcelos JG and Wright SJ (2008) Rapid flow startup in filled horizontal pipelines. Journal of Hydraulic Engineering 134(7): 984-992.

Vasconcelos JG and Wright SJ (2009) Investigation of rapid filling of poorly vented stormwater storage tunnels. Journal of Hydraulic Research 47(5): 547-558.

Vasconcelos JG and Wright SJ (2011) Geysering generated by large air pockets released through water-filled ventilation shafts. Journal of Hydraulic Engineering 137(5): 543-555.

Vasconcelos JG, Wright SJ and Roe PL (2006) Improved simulation of flow regime transition in sewers: two-component pressure approach. Journal of Hydraulic Engineering 132(6): 553-562.

Vasconcelos JG, Wright SJ and Roe PL (2009) Numerical oscillations in pipe-filling bore predictions by shock capturing methods. Journal of Hydraulic Engineering 135(4): 296-305.

Vasconcelos JG, Klaver PR and Lautenbach DJ (2015) Flow regime transition simulations incorporating entrapped air pocket effects. Urban Water Journal 12(6): 488-501.

Wright SJ (2013) Influence of air pocket volume on manhole surge. CHI Journal of Water Management Modeling, http://dx.doi.org/ 10.14796/JWMM.R246-09.

Wright SJ, Creech CT, Lewis JM and Vasconcelos JG (2006) Mechanisms of flow regime transition in rapidly filling stormwater storage tunnels. Environmental Fluid Mechanics 8(5): 605-616.
Wright SJ, Lewis JW and Vasconcelos JG (2011a) Geysering in rapidly filling stormwater tunnels. Journal of Hydraulic Engineering 137(1): 112-115.

Wright SJ, Lewis JW and Vasconcelos JG (2011b) Physical processes resulting in geysers in rapidly filling stormwater tunnels. Journal of Irrigation and Drainage Engineering 137(3): 199-202.

Wright SJ, Determan KV and Vargas SM (2013) Pressure transients due to compression of trapped air in rapidly filling CSO storage tunnels. CHI Journal of Water Management Modelling, http://dx.doi.org/10.14796/JWMM.R245-01.

Wright SJ, Klaver PR and Vasconcelos JG (2016) Assessment of pressure transients due to trapped air compression in rapidly filling combined sewer overflow tunnels. CHI Journal of Water Management Modeling, http://dx.doi.org/10.14796/ JWMM.C399.

Wylie EB and Streeter VL (1982) Fluid Transients. FEB Press, Ann Arbor, MI, USA.

Zhou F, Hicks FE and Steffler PM (2002a) Transient flow in a rapidly filling horizontal pipe containing trapped air. Journal of Hydraulic Engineering 128(6): 625-634.

Zhou F, Hicks FE and Steffler PM (2002b) Observations of air-water interaction in a rapidly filling horizontal pipe. Journal of Hydraulic Engineering 128(6): 635-639.

\section{How can you contribute?}

To discuss this paper, please email up to 500 words to the editor at journals@ice.org.uk. Your contribution will be forwarded to the author(s) for a reply and, if considered appropriate by the editorial board, it will be published as discussion in a future issue of the journal.

Proceedings journals rely entirely on contributions from the civil engineering profession (and allied disciplines). Information about how to submit your paper online is available at www.icevirtuallibrary.com/page/authors, where you will also find detailed author guidelines. 